phase. Even so, the scutching tests indicated increases in fibre yield of up to 30 per cent in crops grown from treated seed.

While it is hoped to make further experiments with these and other methods of seed treatment, it has been decided in the present emergency to treat all home-saved seed with $R D .7846$ at the rate of $6 \mathrm{oz}$. per bushel, if equipment and materials can be made available. Apart from securing a very large measure of control of these and possibly other seed-borne diseases of the flax crop, such treatment, if carefully and regularly carried out, should materially assist in ensuring seed stocks from becoming heavily contaminated with seed-borne parasites.

$R D$. 7846, with tetramethylthiuram disulphide as its effective constituent, has so far produced no phytocidal effect in the crop. Seed grown in 1940 and treated immediately after cleaning in early October has maintained its power of germination unimpaired up to date; this indicates that treatment may be carried out three months prior to sowing without risk of impairing the germination of the seed. RD. 7846 is stated to be non-poisonous, and this claim has been substantiated in so far as no ill effects have been observed on the health of calves and pigeons fed for a considerable period with flax seed heavily dressed with the fungicide.

Ministry of Agriculture, N.I., A. E. MUsketr.

Plant Disease Division,

The Queen's University, Belfast. Jan. 6.

${ }^{1}$ Muskett, A. E., and Colhoun, J., Nature, 146, 32 (1940).

\section{Weighing Living Marine Animals}

GRowTH in marine animals is little understood and offers problems of paramount ecological importance. In the majority of cases, however, considerable difficulties are encountered, partly because of the paucity of material in some cases, and partly because of the difficulty of weighing the animals. To overcome these difficulties a method--the principle of which is given here-is being developed, and it is hoped that problems of growth will thereby be greatly facilitated. So far as I could ascertain its use for such purposes has not been recorded before.

Stated briefly, the method is as follows.

The animal is weighed in ordinary sea-water, the specific gravity $S$ of which is determined. The specific gravity of the water is then slightly altered by the addition of a little distilled water or either sea-salt or concentrated sea-water, and the animal left for some time-long enough to establish a physicochemical equilibrium between the animal's enclosed water and the outside-before it is weighed again. Its weight, which was $w$ in normal sea-water, will consequently change to $w_{1}$. The specific gravity $S_{1}$ of the resulting water at the equilibrium point is also determined. The difference between the values of the two weights divided by the difference between the corresponding specific gravities gives the volume $V$ of the animal minus the internal cavities in communication with the exterior and containing seawater. Therefore :

$$
V=\frac{w-w_{1}}{S_{1}-S} \text { or } V=\frac{\Delta w}{\Delta S}
$$$$
\text { and } W=w+V S=w_{1}+V S_{1} \text {, etc. }
$$

$W=$ weight of the animal in air excluding the water contained in internal cavities in communication with the exterior.

It is thus calculated that a change of 0.01 in the specific gravity of the water causes a change in weight-in-water of $0.1 \mathrm{gm}$. in an animal 10 c.c. and $0.5 \mathrm{gm}$. in an animal $50 \mathrm{c.c}$. in volume, etc.

It is therefore possible to determine the volume and weight-in-air of such animals, excluding the water they contain, by weighing in two samples of water of different but known specific gravities.

Best results are obtained when the specific gravity is changed more than once, and particularly when it is equally increased and decreased. Thus, after the animals are weighed in ordinary sea-water, the specific gravity of the water is raised by $X$ by addition of sea-salt and the corresponding weights are determined. The specific gravity should then be lowered by $X$ also, below the normal, by the addition of appropriate quantities of distilled water. This is in order to obviate any possible interferences due to the effect of the change in osmotic pressure on intra-cellular water.

This method is especially suitable for such animals as sponges, corals, alcyonarians, many other cœlenterates, polyzoans, sipunculids, molluses, echinoderms and similar sluggish or sedentary animals, which possess large cavities in free communication with the outside. Active and free-swimming animals can also be treated in this way after being enclosed in a perforated tube or netting, previously weighed separately in the sea-water used.

The existence of a physico-chemical equilibrium between the internal and external water may be foretold from the morphology and physiology of these animals. In many of them a constant circulation of sea-water is maintained by ciliary movements or muscular contractions. In the latter case, the action may be rhythmic or occasional, a great bulk of water being inhaled by expansion and exhaled by contraction. Robertson ${ }^{1}$ has recently established the identity of the perivisceral fluid of Echinus with that of the sea-water in which it lives. This is also almost undoubtedly the case in the majority of the animals mentioned above.

This method has several advantages over others in common use. Methods based on linear measurements are subject to grave criticism, particularly in contractile animals and those of irregular growth form. Weighing out of water is also inaccurate owing to the great variation in the amount of enclosed sea-water depending on the state of expansion or contraction, as well as the water adhering to the external surface. Taking the dry weight is not more accurate, as it is always difficult to get rid of the salts completely without considerably affecting the actual weight of the animals, either in the process of washing or by the growth of bacteria and otherwise during desicca. tion. The present method possesses none of these drawbacks, and, above all, it has the advantage that it does not involve the killing of the animals. Growth phenomena and effects on the weight of animals produced by various factors can, therefore, be followed in individual animals. By this are avoided the inconveniences of statistical methods where accuracy is approached only by immensely increasing the number of animals dealt with.

\footnotetext{
Marine Biological Station, Fouad I University, Ghardaqa, Red Sea, Egypt. Oct. 25.

${ }^{1}$ Robertson, J. D., J. Exp. Biol., 16, 387 (1939).
} 